\title{
Experiencias
}

\section{Educación para la salud: una experiencia para implementar el uso de la mascarilla en el alumnado con discapacidad visual}

\author{
Health education: an experience to encourage the use of facemasks \\ among students with visual disability
}

N. Rodríguez Mena, B. Campos Rodríguez

\section{Resumen}

La sociedad actual es la sociedad de la imagen. Durante la pandemia, de continuo a los niños y niñas en los hogares, a través de la gran pantalla, se les ofrece como patrón o modelo personas que llevan mascarilla, y es así como su uso se convierte en algo cotidiano. Ante una discapacidad visual, el mensaje que les llega resulta sesgado, pobre, distorsionado e incluso nulo. Las oportunidades de aprendizaje se ven así limitadas, de ahí la necesidad de considerar importante incentivar este hecho nuevo e impactante para todos desde el binomio familiadocente. Tratar de normalizar e instaurar el uso de la mascarilla como práctica habitual en el día a día entre la población más joven pasa a ser una tarea fundamental con un marcado carácter educativo. El personal docente del Equipo Específico de Atención al Alumnado con Discapacidad Visual de Málaga, conscientes de esto, pasan a incorporar este aspecto en el Plan Educativo y a trabajar con el alumnado desde el área de autonomía: educación para la salud. A continuación, se expondrá la experiencia de trabajo desarrollada y que debe ser entendida partiendo del contexto espacio-temporal en el que se generó.

\section{Palabras clave}

Autonomía. Educación para la salud. Familia. Discapacidad visual. Aprendizaje por imitación.

Rodríguez, N., y Campos, B. (2021). Educación para la salud: una experiencia para implementar el uso de la mascarilla en el alumnado con discapacidad visual. RED Visual: Revista Especializada en Discapacidad Visual, 77, 311-317. https://doi.org/10.53094/JJQM4081. 


\begin{abstract}
Today's is the image society. As throughout the pandemic children have been exposed from the flat screens in their homes to role models wearing facemasks, use has become second-nature to them. The message that reaches children with visual disability, however, is biased, weak, distorted or even non-existent. In light of the concomitant narrowing of learning opportunities, a need was identified for families in conjunction with teachers to incentivise wearing this new and impactful facial cover. Furthering the use of facemasks as a routine, everyday practice among the youngest members of society is an essential and characteristically educational task. The teachers on the Team for the Specific Support of Students with Visual Disability working out of Málaga, aware of that fact, included a section on the theme in the curriculum under the unit on independence, entitled 'health education'. This article describes the respective working experience, which should be understood within the time-space context in which it was conducted.
\end{abstract}

\title{
Key words
}

Independence. Health education. Family. Visual disability. Emulation learning.

\section{Introducción}

El confinamiento llega de repente. Se declara el estado de alarma y ello supone el hecho de que toda la población deba permanecer recluida en sus hogares, quedando suspendida cualquier actividad no esencial.

Día tras día, se suceden noticias preocupantes y, a veces, contradictorias que llegan a través de los medios de comunicación. Muy pronto, el uso de la mascarilla se vislumbra como algo conveniente para tratar de contener la transmisión comunitaria del virus $y$, aunque pasa a convertirse en un tema polémico de debate continuo, va cobrando fuerza el interés hacia su uso.

Es así como este artículo presenta una fuerte demanda en el mercado, pasando a ser, al mismo tiempo, un bien escaso y necesario. Todo ello desemboca en el hecho de que comiencen a sucederse iniciativas solidarias de grupos organizados para la elaboración de mascarillas caseras a fin de llegar, en principio, a los colectivos más vulnerables y esenciales: residencias de mayores, bomberos, fuerzas de orden público y hospitales.

Rodríguez, N., y Campos, B. (2021). Educación para la salud: una experiencia para implementar el uso de la mascarilla en el alumnado con discapacidad visual. RED Visual: Revista Especializada en Discapacidad Visual, 77, 311-317. https://doi.org/10.53094/JJQM4081. 
De forma general y absoluta, la sociedad se encuentra inmersa en una situación extrema nunca vivida ni imaginada y de la que es necesario salir cuanto antes. A medida que los datos pandémicos proyectan cierto alivio, urge restaurar el orden social, y así se acuña el término de «nueva normalidad». Las autoridades comienzan a establecer horarios de paseos por tramos de edad. Uno de los colectivos prioritarios son los niños y niñas. ¿Están preparados para ello? ¿De qué forma les estará afectando esta situación increíblemente increíble?

\section{Justificación de la experiencia}

Los distintos profesionales del equipo educativo especializado, como agentes sociales comprometidos en el desempeño de su trabajo, han de hacer frente a los cambios y problemáticas impuestos por la pandemia. Sin duda, estamos ante un hecho que marcará un antes y un después y que viene cargado de daños colaterales.

Así, han de intervenir ofreciendo una respuesta educativa conectada con la realidad y ajustada a las circunstancias que se están viviendo. Las familias deben encontrar en ellos un buen sostén para ayudarlos en el difícil arte de educar. Las dinámicas familiares se han visto rotas. Es así que comienzan por aconsejar recuperar rutinas de paseo con sus hijos e hijas.

Las primeras salidas, sin duda, suponen todo un reto. Llegan de la mano de nuevas normas de convivencia establecidas por las autoridades sanitarias del país. A saber: distancia social, limitación de aforos, uso obligatorio de mascarillas.

Los niños han de aceptar novedades y cambios. Uno de los primeros escollos a salvar será el de la mascarilla. Se aconseja su uso y se comienza a apuntar como un imprescindible en nuestras vidas durante un tiempo largo e incierto. Casi todos los críos en principio la rechazan: se trata de un accesorio extraño y molesto. Por otra parte, se da la circunstancia de que aún es difícil conseguirlas.

\section{Desarrollo de la experiencia: Boquitas bien tapadas y sonrisa en la mirada}

Diferentes profesionales pertenecientes a los equipos específicos de atención al alumnado con discapacidad visual, con este simpático eslogan, se plantean el diseño

Rodríguez, N., y Campos, B. (2021). Educación para la salud: una experiencia para implementar el uso de la mascarilla en el alumnado con discapacidad visual. RED Visual: Revista Especializada en Discapacidad Visual, 77, 311-317. https://doi.org/10.53094/JJQM4081. 
y desarrollo de esta actividad enmarcada dentro del área de autonomía: educación para la salud.

La actividad consiste en enviar por correo postal al domicilio de cada alumno un sobre tipo carta, dirigido a su nombre, que contiene una mascarilla casera junto a un mensaje positivo de su maestro de apoyo. Se trata de un gesto que ofrezca acompañamiento, cercanía y seguridad en tiempos tan inquietantes y complicados, intentando empatizar e incentivar su uso.

Tres son las fases de esta actividad.

\section{Fase 1}

Confección de mascarillas de elaboración casera por parte de una maestra, conforme a las primeras directrices marcadas desde el ámbito sanitario estatal: dos capas de tela (tejido de algodón y TNT -tejido no tejido-) (ver Figura 1). Además, en la confección de las mascarillas se tienen en cuenta las siguientes indicaciones:

- Tallaje adecuado: pequeño, mediano o grande de modo que ajuste a cada lado del rostro de forma ceñida pero cómoda.

- Colocación con gomas suaves enganchadas a las orejas. Resulta así una forma fácil de «quita y pon».

- Durabilidad y mantenimiento, admitiendo lavados a $60^{\circ}$ en lavadora.

Figura 1. Mascarillas caseras preparadas para su envío

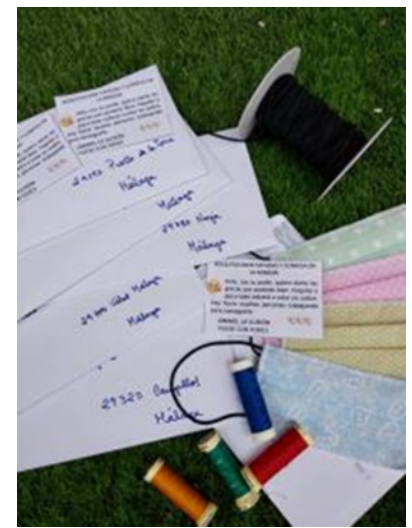

Rodríguez, N., y Campos, B. (2021). Educación para la salud: una experiencia para implementar el uso de la mascarilla en el alumnado con discapacidad visual. RED Visual: Revista Especializada en Discapacidad Visual, 77, 311-317. https://doi.org/10.53094/JJQM4081. 


\section{Fase 2}

En nombre de cada maestro, se hace el envío, por correo postal, al alumnado, así como a hermanos, hermanas y familiares convivientes, de una mascarilla de elaboración casera, al tiempo que se les hace llegar un mensaje de ánimo, cariño e incentivo para usar la mascarilla.

Se diseñan dos tipos de mensaje en función de la edad del alumnado (ver Figura 2).

Figura 2. Mensaje enviado al alumnado de infantil y primaria

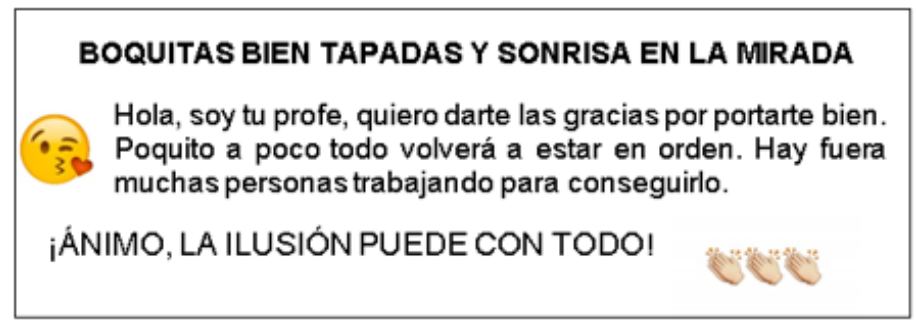

Al alumnado de secundaria, apostando, ahora más que nunca, por destacar el interés en el uso de las nuevas tecnologías, se les hace llegar, de igual forma, una cita de Albert Einstein que se acompaña de un código QR, cuyo enlace lleva a la música que pasa a convertirse en todo un himno de la pandemia: Resistiré (ver Figura 3).

Figura 3. Mensaje enviado al alumnado de secundaria

\section{Hay una fuerza motriz más poderosa que el vapor, la electricidad y la energía atómica: la voluntad. \\ Albert Einstein}

\section{Fase 3}

Tras la recepción de la mascarilla, cada profesional inicia un trabajo personal e individualizado con el alumnado y su familia a través de videollamada, tratando diversos aspectos de interés. Entre los cuales se podrían destacar:

- Necesidad de establecimiento de rutinas de uso (cómo ponerse y quitarse la mascarilla). En este sentido, se pone en valor el papel del adulto como modelo y la importancia del aprendizaje por imitación en las primeras edades. 
- Invitar a la reflexión en relación a la actitud general con la que debemos afrontar el día a día, tratando de crear un clima de calma y seguridad desde la responsabilidad individual y controlando miedos.

- Uso correcto y mantenimiento de las mascarillas: se deben lavar en función de la frecuencia con la que se utilicen.

- Se recuerda también que es importante no tocarse los ojos, la nariz y la boca al retirarla de la cara, así como lavarse las manos inmediatamente después de tocarla.

- No son recomendables para niños menores de 2 años o aquellos que tengan problemas respiratorios o que no puedan quitársela sin ayuda.

En general, se abordan aspectos relacionados con la temática que se van generando y cambiando de continuo.

\section{Conclusiones}

Una actividad que, en principio, se presume como algo simple y puntual llega a descubrir nuevos espacios educativos de encuentro y reflexión muy interesantes, especialmente con las familias, pasando a convertirse en todo un eje vertebrador sobre el que trabajar en muchos otros aspectos con el alumnado.

De forma unánime, es acogida con enorme interés y agradecimiento por todas las partes. El propio eslogan con el que se presenta, Boquitas bien tapadas y sonrisa en la mirada, la forma inusual y tradicional en la que se lleva a cabo (recepción de una carta) y el momento tan especial, destilan una fuerte carga afectiva. Todo ello, unido al sentimiento generalizado de vulnerabilidad que se padece, resultan ingredientes perfectos para generar un clima de acercamiento y trabajo en equipo, familia-docente, tan necesario siempre y ahora más que nunca.

Queda así patente la importancia que reviste el papel del profesional docente, tan cuestionado en los últimos tiempos frente al impacto tecnológico que nos invade sin remisión.

Rodríguez, N., y Campos, B. (2021). Educación para la salud: una experiencia para implementar el uso de la mascarilla en el alumnado con discapacidad visual. RED Visual: Revista Especializada en Discapacidad Visual, 77, 311-317. https://doi.org/10.53094/JJQM4081. 
Nuestra realidad ahora es otra y la tarea educativa no puede volver la espalda a este hecho. El cambio de paradigma se hace más urgente y queda más justificado que nunca. Tiempos de transformación que se deben afrontar como nuevas oportunidades para avanzar.

Nuria Rodríguez Mena. Maestra del Equipo Específico para el Alumnado con Discapacidad Visual. Dirección de Zona de la ONCE en Málaga. Cuarteles, 8; 29002 Málaga (España). Correo electrónico: nrme@once.es.

Beatriz Campos Rodríguez. Técnica de rehabilitación de la Delegación Territorial de la ONCE en Castilla-La Mancha. Agencia de la ONCE en Guadalajara. Alvarfáñez de Minaya, 6; 19001 Guadalajara (España). Correo electrónico: becr@once.es. 